\title{
Hodgkin lymphoma presenting as Hemophagocytic Lymphohistiocytosis: A case report and review of published cases
}

\author{
Somaia M. Mousa \\ Clinical Pathology Department, Kasr Al-Ainy School of Medicine, Cairo University, Cairo, Egypt.
}

Introduction: Hemophagocytic lymphohistiocytosis (HLH) is a serious syndrome that occurs in association with malignancy, infections and autoimmune diseases.

Case presentation: A 30 years old female patient presented with fever, splenomegaly, pancytopenia, hyperferritinemia, hypertriglyceridemia and hemophagocytosis in bone marrow aspirate. She was initially diagnosed as HLH. Bone marrow biopsy revealed the presence of Hodgkin lymphoma.

Discussion: The most common HLH associated-malignancy is T/natural killer cell lymphoma and less commonly diffuse large B-cell lymphoma. The combination of HLH and Hodgkin lymphoma is rare. A strong association between Hodgkin lymphoma associated HLH and Epstein Barr virus (EBV) infection has been discussed in published case reports. Hodgkin lymphoma may be a cause of HLH and their relation with EBV has to be investigated.

Key words: Hemophagocytic lymphohistiocytosis (HLH); Hodgkin lymphoma; Epstein Barr virus (EBV). Corresponding author: Somaia M. Mousa, MD, Clinical Pathology Department, Kasr Al-Ainy School of Medicine, Cairo University, Cairo, Egypt.

E-mail: somaiamousa@kasralainy.edu.eg

Received: 26 September 2016, Accepted: 6 October 2016

\section{INTRODUCTION}

Hemophagocytic Lymphohistiocytosis (HLH), also known as hemophagocytic syndrome, is a life threatening syndrome resulting from over stimulation of the immune system leading to uncontrolled production of cytokines (hypercytokinemia or cytokine storm) with subsequent macrophages proliferation and hemophagocytosis ${ }^{1}$. Based on the underlying etiology, HLH can be classified into either primary (genetic) or secondary (acquired). Primary HLH occurs in patients with genetic abnormalities that alter the cytotoxic function of natural killer (NK) cells and T lymphocytes ${ }^{2}$. While, the secondary HLH occurs in association with infections (particularly viral infection), autoimmune diseases and malignancy.

Lymphomas are the most common cause of malignancy associated HLH particularly non-Hodgkin lymphoma (NHL). HLH associated with Hodgkin lymphoma has been rarely reported. ${ }^{1}$

Guidelines currently available for diagnosis of HLH are those provided by the Histiocyte Society in $2004^{3}$, upon which patients should have at least 5 out of 8 criteria to be diagnosed as HLH. These criteria include fever, splenomegaly, bi or pancytopenia in the peripheral blood, elevated ferritin level $(\geq 500 \mu \mathrm{g} / \mathrm{L})$, hypertriglyceridemia and/ or hypofibrinogenemia, hemophagocytosis in the bone marrow, spleen, or lymph nodes, low/or absent NK-cell activity and high levels of soluble CD25.

We herein report a case of HLH that is found to be the initial manifestation of Hodgkin lymphoma.

\section{CASE REPORT}

A 30-years old female patient admitted to the Hospital of Kasr Al-Ainy School of Medicine, in May, 2016. She was complaining of high fever for 2 weeks, easy fatigability, weight loss and night sweating. Pancomputerized tomography revealed huge splenomegaly together with bilateral axillary and cervical lymphadenopathy.

Laboratory data of the patient at admission are shown in Table 1. The patient had high ferritin and high triglyceride levels. Complete blood count (CBC) revealed pancytopenia, upon which bone marrow aspirate/ 


$\begin{array}{llll}\text { Vol. } 12 \text { No. } 1 & 2016 & \text { Somaia M. Mousa }\end{array}$

biopsy (BMA/B) was done. BMA was normocellular. The myeloid series showed toxic granulations and mild eosinophilia, while the erythroid series revealed megaloblastoid changes. Megakaryocytes were increased in number with normal morphology and platelet budding. Plasma cells were increased by scanning.

Macrophages were increased in number with signs of hemophagocytosis (Figure 1). Taken together, our patient fulfilled 6 out of 8 criteria for diagnosis of HLH. A few-days later, BMB was examined and revealed the presence of a granuloma formed of macrophages, plasma cells and eosinophils with large immature cells with evident nucleoli within. These cells were positive for CD30 by immunohistochemistry.

Based on the aforementioned findings, our patient was diagnosed as stage IV Hodgkin lymphoma complicated with HLH.

Table 1: Laboratory data of our patient at admission

\begin{tabular}{|c|c|c|}
\hline Parameter & Value & Reference range \\
\hline $\operatorname{TLC}(/ \mu \mathrm{L})$ & 1500 & $4000-10000$ \\
\hline Hemoglobin (g/dL) & 5.8 & $12-14.5$ \\
\hline Platelets $\left(\mathrm{X} 10^{3} / \mu \mathrm{L}\right)$ & 111 & $150-450$ \\
\hline Total bilirubin (mg/dL) & 0.3 & $0.3-1.3$ \\
\hline $\operatorname{AST}(\mathbf{U} / \mathbf{L})$ & 26 & $10-40$ \\
\hline $\operatorname{ALT}(\mathbf{U} / \mathbf{L})$ & 10 & $7-56$ \\
\hline LDH (U/L) & 481 & $140-280$ \\
\hline Urea (mg/dL) & 32 & $8-20$ \\
\hline Creatinine (mg/dL) & 0.4 & $0.4-0.8$ \\
\hline Triglyceride (mg/dL) & 216 & $<150$ \\
\hline Ferritin $(\mu \mathrm{g} / \mathrm{L})$ & 15140 & $11-307$ \\
\hline Fibrinogen (mg/dL) & 658 & $150-400$ \\
\hline $\mathrm{Na}(\mathrm{mmol} / \mathrm{L})$ & 127 & $135-145$ \\
\hline $\mathrm{K}(\mathbf{m m o l} / \mathbf{L})$ & 3.1 & $3.5-5$ \\
\hline Protein (g/dL) & 7 & $6.4-8$ \\
\hline Albumin (g/dL) & 2.6 & $3.5-5$ \\
\hline
\end{tabular}

TLC: total leukocyte count, AST: aspartate aminotransferase, ALT: alanine aminotransferase, LDH: lactate dehydrogenase, Na: Sodium, K: Potassium.

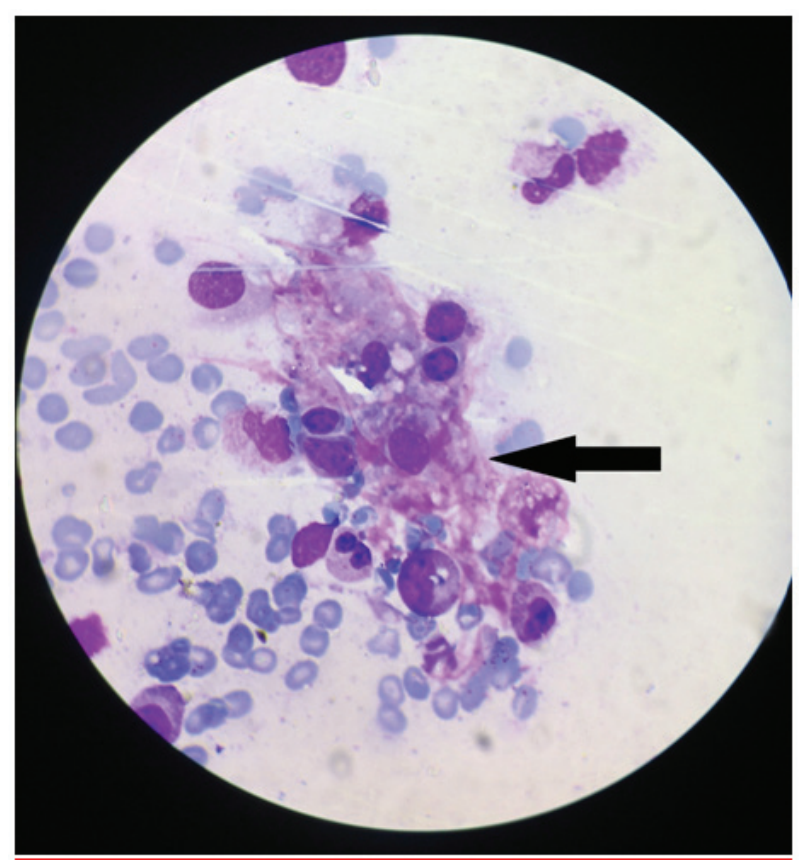

Figure 1: Bone marrow aspirate smear showing macrophages with hemophagocytosis (Giemsa stain, $\times 1000$ ).

\section{DISCUSSION}

HLH is a potentially fatal disease. Thus main challenge for treatment of HLH patients is making prompt diagnosis together with search for the underlying cause to initiate a specific therapy.

Malignancy is the most common cause of secondary HLH particularly hematological malignancy. Because it has an aggressive fatal course, proper investigation and treatment of the underlying cause could save patient's life.

Lymphoma-associated HLH has been reported with T/NK-cell lymphoma and diffuse large B-cell lymphoma ${ }^{4}$. A cohort study of 264 patients with hemophagocytosis revealed that malignancy was the underlying cause in $64 \%$ of cases, of which $96 \%$ had hematological malignancy, whereas, non Hodgkin lymphomas were the most common $(54 \% \mathrm{~T} / \mathrm{NK}$ cell and $32 \% \mathrm{~B}$ cell) and no case of Hodgkin lymphoma associated with $\mathrm{HLH}^{5}$.

Although Hodgkin lymphoma-associated HLH (HL-HLH) is less common, several case reports have been published. In a case series of 34 patients with HL-HLH, one of the main features of this disease is its strong association with Epstein-Barr virus (EBV) infection. Viral proteins were detected in tumor cells 
(Hodgkin cells or Reed-Sternberg cells) among 32 out of 34 patients $(94 \%)^{6}$. On the other hand. EBV was detected in only $40 \%$ of cases of Hodgkin lymphoma not associated with $\mathrm{HLH}^{7}$.

The association between EBV and HL-HLH was evident in other published case reports ${ }^{8-17}$. Besides, EBV infection has been considered as the most common cause of infection induced $\mathrm{HLH}^{18}$. About one third of adult patients with secondary HLH have more than one underlying cause ${ }^{19}$. This may explain the occurrence of HLH in association with both Hodgkin lymphoma and EBV that is assumed to be due to viral protein expression by infected tumor cells which result in the production of large amounts of cytokines with subsequent $\mathrm{HLH}^{6}$.

Conclusion: This case emphasizes the importance of considering Hodgkin lymphoma as an underlying cause of HLH. The causative relation between EBV infection and HL-HLH needs to be properly investigated.

\section{REFERENCES}

1. Otrock ZK, Eby CS. Clinical characteristics, prognostic factors, and outcomes of adult patients with hemophagocytic lymphohistiocytosis. Am J Hematol. 2015; 90(3): 220-224.

2. Rosado FG, Kim AS. Hemophagocytic lymphohistiocytosis: an update on diagnosis and pathogenesis. Am J Clin Pathol. 2013; 139(6): 713-727.

3. Henter JI, Horne A, Aricó M, et al. HLH-2004: Diagnostic and therapeutic guidelines for hemophagocytic lymphohistiocytosis. Pediatr Blood Cancer. 2007; 48(2): 124-131.

4. Han AR, Lee HR, Park BB, et al. Lymphoma-associated hemophagocytic syndrome: clinical features and treatment outcome. Ann Hematol. 2007; 86(7): 493-498.

5. Lim SH, Park S, Jang JH, et al. Clinical significance of bone marrow hemophagocytosis in adult patients with malignancy and non-malignancy-induced hemophagocytic lymphohistiocytosis. Ann Hematol. 2016; 95(2): 325-335.

6. Ménard F, Besson C, Rincé P, et al. Hodgkin lymphoma associated hemophagocytic syndrome: a disorder strongly correlated with Epstein-Barr virus. Clin Infect Dis. 2008; 47: 531-534.
7. Glaser SL, Lin RJ, Stewart SL, et al. Epstein-Barr virus-associated Hodgkin's disease: epidemiologic characteristics in international data. Int J Cancer. 1997;70 (4): 375-382.

8. Kojima H, Takei N, Mukai Y, et al. Hemophagocytic syndrome as the primary clinical symptom of Hodgkin's disease. Ann Hematol. 2003; 82(1): 53-56.

9. Hasselblom S, Linde A, Ridell B. Hodgkin's lymphoma, Epstein-Barr virus reactivation and fatal haemophagocytic syndrome. J Intern Med. 2004; 255(2): 289-295.

10. Chan K, Behling E, Strayer DS, Kocher WS, Dessain SK. Prolonged hemophagocytic lymphohistiocytosis syndrome as an initial presentation of Hodgkin lymphoma: a case report. J Med Case Rep. 2008; 2: 367.

11. Flew SJ, Radcliffe KW. Haemophagocytic lymphohistiocytosis complicating Hodgkin's lymphoma in an HIV-positive individual. Int J STD AIDS. 2010; 21(8): 601-603.

12. Hagihara M, Inoue M, Hua J, Iwaki Y. Lymphocyte-depleted Hodgkin lymphoma complicating hemophagocytic lymphohistiocytosis as an initial manifestation: a case report and review of the literature. Intern Med. 2012; 51(21): 3067-3072.

13. Morita $Y$, Kenzaka $T$, Yoshimoto $H$, Ohno N. Hodgkin's lymphoma preceded by haemophagocytic lymphohistiocytosis. BMJ Case Rep. 2013; 2013. pii: bcr2013010129.

14. Tatara R, Sato M, Fujiwara S, et al. Hemoperfusion for Hodgkin lymphoma-associated hemophagocytic lymphohistiocytosis. Intern Med. 2014; 53(20): 2365-2368.

15. Morita Y, Emoto M, Serizawa K, et al. HIV-negative Primary Bone Marrow Hodgkin Lymphoma Manifesting with a High Fever Associated with Hemophagocytosis as the Initial Symptom: A Case Report and Review of the Previous Literature. Intern Med. 2015; 54(11): 1393-1396.

16. Domínguez-Muñoz MÁ, Morales-Camacho RM, Prats-Martín $\mathrm{C}$, et al. Unusual co-occurrence of Hodgkin lymphoma and hemophagocytic lymphohistiocytosis in a bone marrow aspirate. Ann Hematol. 2016; 95(6): 1019-1021.

17. Ichikawa S, Takahashi T, Katsushima H, Fukuhara N, Ichinohasama R, Harigae H. Advanced Lymphocyte-rich Classical Hodgkin Lymphoma Complicated with Fatal Hemophagocytic Syndrome. Intern Med. 2016; 55(2): 191-196.

18. Maakaroun NR, Moanna A, Jacob JT, Albrecht H. Viral infections associated with haemophagocytic syndrome. Rev Med Virol. 2010; 20(2): 93-105.

19. Ramos-Casals M, Brito-Zerón P, López-Guillermo A, Khamashta MA, Bosch X. Adult haemophagocytic syndrome. Lancet. 2014; 383(9927): 1503-1516. 